\title{
Location Selection for Wind Plant using AHP and Axiomatic Design in Fuzzy Environment
}

\author{
Merve Cengiz Toklu ${ }^{1}$, Özer Uygun ${ }^{2}$ \\ ${ }^{1,2}$ Department of Industrial Engineering, Sakarya University
}

\begin{tabular}{l}
\hline \hline Article Info \\
\hline Article history: \\
Received Sept 10, 2018 \\
Revised Oct 23, 2018 \\
Accepted Oct 26, 2018 \\
\hline
\end{tabular}

\section{Keyword:}

Renewable energy resources

Wind power

Fuzzy logic

AHP

Axiomatic design

\begin{abstract}
Electricity consumption of the world has been increasing due to increasing population and production amounts, developing technology and increasing automation level. Studies show that the increase will continue in the future and the supply and demand amount should increase depending on the changing world. Renewable energy sources have become crucial due to the traditional energy sources like coal harm the environment nature and human health. Nowadays countries pay more attention to use their own resources in order to maintain their socio-economic and political independence. As awareness of clean energy increases, the usage of renewable energy sources is increasing. The investment costs of renewable energy sources are very high. For this reason, the selection of the location for renewable energy sources is a strategic decision that getting it right the first time. Different criteria are evaluated when selecting the installation location. The priorities of these criteria may be different from each other. In this study, a model was proposed for selecting the location for the installation of wind power plant via using fuzzy AHP and fuzzy Axiomatic Design methods. In the implementation phase of the model, evaluation criteria have been determined and prioritized. In the light of the evaluation criteria, 3 locations have been evaluated and the most suitable one was selected.
\end{abstract}

\section{Corresponding Author:}

Merve Cengiz Toklu

Department of Industrial Engineering,

Sakarya University,

Faculty of Engineering, Serdivan, Sakarya, Turkey,

Email: mtoklu@sakarya.edu.tr

\section{Introduction}

Increasing energy demand due to changing world dynamics has caused countries to turn towards renewable energy sources such as solar, wind, nuclear, biomass and geothermal since they are economical, environmentally friendly and renewable. Wind energy is a type of renewable energy sources that do not harm the environment. The negative sides of the wind energy are that the construction costs are very high and the unit capacity is not very sufficient. Wind tribunes that built in the in windy regions transform the kinetic energy of the moving air, primarily to mechanic energy, and then to electrical energy [1]. The energy from the wind depends on such factors as the speed and intensity of the wind. These factors vary from region to region. For this reason, the selection of a location for wind turbines has an important role for the generation of the energy. Location evaluation and selection are the complex multi-criteria problems because of considering different evaluation criteria. These criteria may be contradictory and uncertain. For this reason, multi-criteria decision making (MCDM) methods can be used. There are many studies in the literature about the selection of renewable energy sources. Generally, MCDM methods are used [2]-[9] in these studies.

When the literature is examined, it is seen that there are also studies on the location selection for renewable energy source installation. Aras et al. [10] determined the suitable location for a wind observation station with the analytic hierarchy process (AHP) method. Zhu and Cheung [11] proposed a model based on the fuzzy set 
theory for selecting the location of the wind farm. Azadeh et al. [12] selected the wind plants location with data envelopment analysis technique. Haaren and Fthenaki [13] proposed a method to select wind turbine farms based on a spatial cost-revenue optimization. Choudhary and Shankar [14] proposed a model for evaluation of the most appropriate location for thermal power plants by using AHP and Technique for Order of Preference by Similarity to Ideal Solution (TOPSIS) methods. Yun-na et al. [15] applied the matter-element extension and ideal matter-element extension methods to evaluate sites for the wind/solar hybrid power systems. Chatterjee and Bose [16] evaluated the locations for the wind farm by using complex proportional assessment based MCDM methodology under fuzzy environment. Atici et al. [17] proposed a selection model for wind power plants by using geographic information systems (GIS) and the ELECTRE method. Latinopoulos and Kechagia [18] proposed a model for evaluating the wind-farm sites by using GIS and spatial multi-criteria decision analysis. Sajid et al. [19] used GIS and fuzzy AHP method to realize the optimum site selection decision. Wang et al. [20] combined 3 MCDM methods which are the fuzzy AHP, data envelopment analysis, and TOPSIS to select solar power plant site. Daneshvar Rouyendegh et al.[21] proposed a method to select wind energy plant site by using intuitionistic fuzzy TOPSIS method.

In addition to these studies, Axiomatic Design (AD) method has been rarely used for the selection of renewable energy installation locations. Boran et al. [22] evaluated sites for grid-connected photovoltaic power plants by using $\mathrm{AD}$ approach. Khandekar et al. [23], used fuzzy AD method to evaluate the small hydro-power plants.

In some studies, the potential of energy systems has been investigated. Ariza Taba et al. [24] evaluated the energy potential of photovoltaic systems in the Caribbean region of Colombia and improved the solar energy atlas for this region by using ArcGIS software. Likewise, Mwanza et al. [25] evaluated the solar energy resource distribution and potential in Zambia by using ArcGIS software. Yeşilyurt et al. [26] examined the wave energy potential in Turkey.

To the best of our knowledge, there have been only a few studies on the location selection for renewable energy source installation via fuzzy AHP and fuzzy AD methods. In this study, a model was proposed to select the location for the installation of wind power plant by using fuzzy AHP and fuzzy AD methods. The remainder of the study is organized as follows: In the second section, fuzzy AHP and fuzzy AD methods are described. In the third section, the proposed model is described. In the Application section, evaluation criteria have been determined and prioritized. In the light of the evaluation criteria, 3 locations (Location-A, Location-B, and Location-C) were evaluated and the most suitable place was selected in the results. Finally, the conclusions of the application and future studies are discussed in the Conclusions section.

\section{Materials and methods}

In this section, the methods used in the study are briefly described. In the proposed model, fuzzy AHP method is used to prioritize the evaluation criteria set. Once the priorities have been determined, the appropriate location selection has been carried out using the fuzzy Axiomatic Design method.

\subsection{Fuzzy Analytic Hierarchy Process}

AHP [27], is one of the most frequently used MCDM technique for selection, evaluation, and prioritization problems. In the AHP method, the priorities are obtained from the results of the pairwise comparisons carried out by the decision makers (DMs). With this methodology, both objective and subjective criteria can be evaluated at the same time. DM's answers include linguistic expressions such as good, very good. For this reason in this study, Chang's extent analysis method [28] which is the one of fuzzy approach to AHP was used. The linguistic terms and their corresponding triangular fuzzy numbers (TFNs) are shown in Table 1.

Table 1. The linguistic terms and TFNs (adapted from [28])

\begin{tabular}{lcc}
\hline Linguistic terms & TFNs & Triangular fuzzy reciprocal numbers \\
\hline Equally Important & $(1,1,1)$ & $(1,1,1)$ \\
Weekly Important & $(1,3,5)$ & $(1 / 5,1 / 3,1)$ \\
Strongly Important & $(3,5,7)$ & $(1 / 7,1 / 5,1 / 3)$ \\
Very Important & $(5,7,9)$ & $(1 / 9,1 / 7,1 / 5)$ \\
Absolutely Important & $(7,9,9)$ & $(1 / 9,1 / 9,1 / 7)$ \\
\hline
\end{tabular}


Chang's method [28] is described below.

Let $X=\left\{x_{1}, x_{2}, \ldots, x_{n}\right\}$ be an object set, and $G=\left\{g_{1}, g_{2}, \ldots, g_{m}\right\}$ be a goal set.

$M_{g_{i}}^{1}, M_{g_{i}}^{2}, \ldots, M_{g_{i}}^{m}, \quad i=1,2, \ldots, n$ where all the $M_{g_{i}}^{j}(j=1,2, \ldots, m)$ are TFNs.

$$
\begin{gathered}
S_{i}=\sum_{j}^{m} M_{g_{i}}^{j} \otimes\left[\sum_{i=1}^{n} \sum_{j=1}^{m} M_{g_{i}}^{j}\right]^{-1} \\
\sum_{j}^{m} M_{g_{i}}^{j}=\left(\sum_{j=1}^{m} l_{j}, \sum_{j=1}^{m} m_{j}, \sum_{j=1}^{m} u_{j}\right) \\
\sum_{i=1}^{n} \sum_{j=1}^{m} M_{g_{i}}^{j}=\left(\sum_{i=1}^{n} l_{i}, \sum_{i=1}^{n} m_{i}, \sum_{i=1}^{n} u_{i}\right) \\
{\left[\sum_{i=1}^{n} \sum_{j=1}^{m} M_{g_{i}}^{j}\right]^{-1}=\left(\frac{1}{\sum_{i=1}^{n} u_{i}}, \frac{1}{\sum_{i=1}^{n} m_{i}}, \frac{1}{\sum_{i=1}^{n} l_{i}}\right)}
\end{gathered}
$$

$M_{2}=\left(l_{2}, m_{2}, u_{2}\right) \geq M_{1}=\left(l_{1}, m_{1}, u_{1}\right)$ is defined as $V\left(M_{2} \geq M_{1}\right)=\sup \left[\min \left(\mu_{M_{1}}(x), \mu_{M_{2}}(y)\right)\right]$

$$
V\left(M_{2} \geq M_{1}\right)=\operatorname{hgt}\left(M_{1} \cap M_{2}\right)=\mu_{M_{2}}(d)=\left\{\begin{array}{cl}
1, & \text { if } m_{2} \geq m_{1}, \\
0, & \text { if } l_{1} \geq u_{2}, \\
\frac{l_{1}-u_{2}}{\left(m_{2}-u_{2}\right)-\left(m_{1}-l_{1}\right)}, & \text { otherwise, }
\end{array}\right.
$$

where $d$ is the ordinate of the highest intersection point $d$ between $\mu_{M_{1}}$ and $\mu_{M_{2}}$. Both values of $V\left(M_{1} \geq M_{2}\right)$ and $V\left(M_{2} \geq M_{1}\right)$ are required in order to compare $M_{1}$ and $M_{2}$.

$$
\begin{gathered}
V\left(M \geq M_{1}, M_{2}, \ldots, M_{k}\right)=V\left[\left(M \geq M_{1}\right) \text { and }\left(M \geq M_{2}\right) \text { and } \ldots \text { and }\left(M \geq M_{k}\right)\right] \\
=\min V\left(M \geq M_{i}\right), \quad i=1,2, \ldots, k . \\
\text { Assume that } d^{\prime}\left(A_{i}\right)=\min V\left(S_{i} \geq S_{k}\right) \text { for } k=1,2, \ldots, n ; k \neq i . \\
W^{\prime}=\left(d^{\prime}\left(A_{1}\right), d^{\prime}\left(A_{2}\right), \ldots, d^{\prime}\left(A_{n}\right)\right)^{T}, \text { where } A_{i}(i=1,2, \ldots, n) \text { are } n \text { elements. } \\
W=\left(d\left(A_{1}\right), d\left(A_{2}\right), \ldots, d\left(A_{n}\right)\right)^{T}, \text { where } W \text { is a non-fuzzy number. }
\end{gathered}
$$

\subsection{Fuzzy Axiomatic Design}

The Axiomatic Design method is developed by Suh [21,22] to contributes structure to design process for engineers. Suh defined two axioms in the AD. Axiom 1 is the "Independence Axiom" and axiom 2 is the "Information Axiom". Second axiom is used to select the most suitable alternative if there are more than one acceptable choice [21,22]. Information content $\left(\mathrm{I}_{\mathrm{i}}\right)$ is related to the probability of capturing the design targets. The information content has been used to give a decision in many different problems [31].

$$
I_{i}=\log _{2}\left(\frac{1}{P_{i}}\right)
$$

where $p_{i}$ is the probability of meeting a given functional requirements $\left(\mathrm{FR}_{\mathrm{i}}\right)$ [32].

$$
\begin{gathered}
P_{i}=\left(\frac{\text { common range }}{\text { system range }}\right) \\
I_{i}=\log _{2}\left(\frac{\text { system range }}{\text { common range }}\right)
\end{gathered}
$$

System range, design range and the common area (acceptable solution) are shown in Figure 1. 


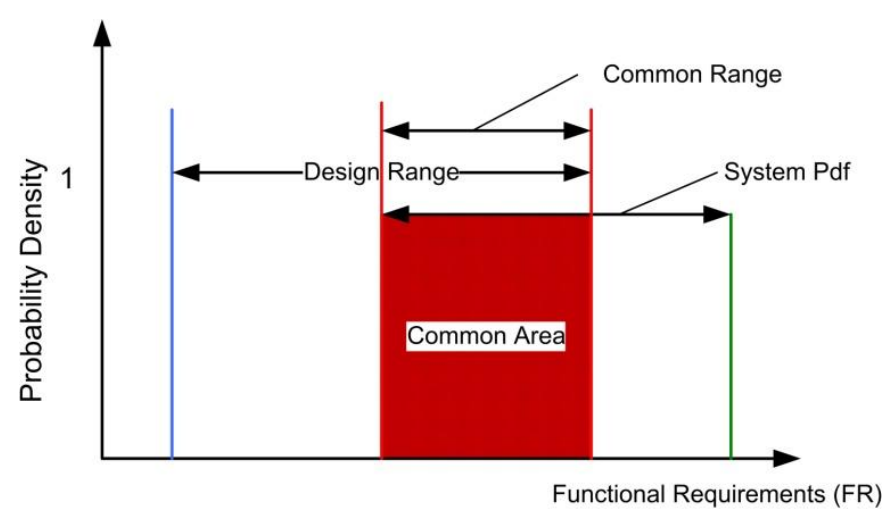

Figure 1. Design range, system range and common range [24,25]

In real-world problems, there may be missing information about the system and design ranges. In the case of decision makers applying linguistic expressions in the Axiomatic Design, the fuzzy AD becomes a solution method. Kulak and Kahraman approached the AD method with a view of fuzzy logic in their studies [31][34]. According to Kulak and Kahraman, "a membership function of triangular or trapezoidal fuzzy number exist in the fuzzy AD whereas a probability density function (Pdf) exist in the crisp case" [32]. In this approach, the common area can be calculated by using the intersection area of triangular or trapezoidal fuzzy numbers. Consequently, information content is given by [32]:

$$
I_{i}=\log _{2}\left(\frac{T F N \text { of system design }}{\text { common area }}\right)
$$

The common area between the design range and system range is shown in Figure 2.

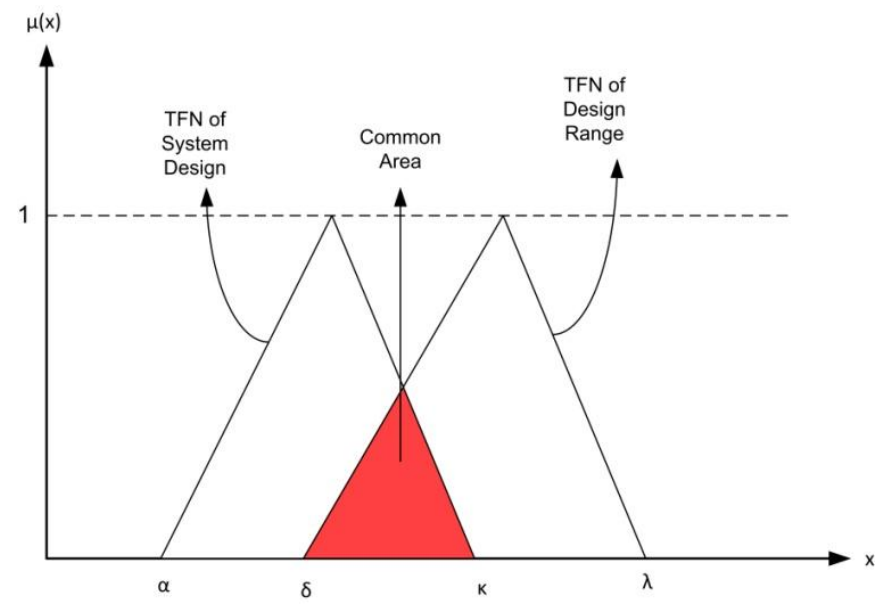

Figure 2. The common area between design range and system range [24,25]

In the classical $\mathrm{AD}$ method, all criteria are assumed to be of equal weight. If the problem needs to designate a different weight for each criterion, the following weighted AD approach can be used [32].

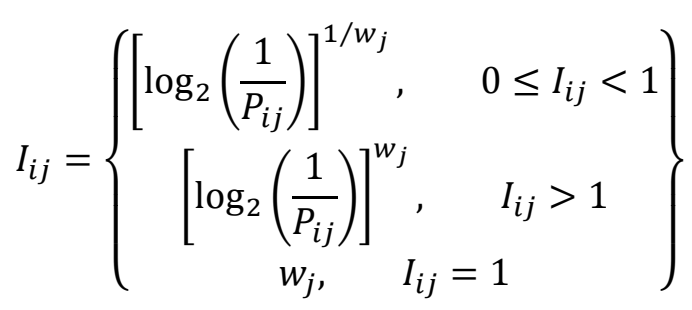




\section{Proposed Model}

The proposed model is aimed to select the most appropriate location for wind turbines. As mentioned before, the location selection for wind turbines is an important and strategic decision due to affects the amount of generated energy directly. It is important to determine the criteria affecting the location selection and to decide on the location by taking these criteria into consideration simultaneously.

Main steps of the proposed model are shown in Figure 3. The first step is about defining the criteria set. These criteria directly affect the amount of generated energy. However, each criterion may not affect the result with the same effect level. In the second step, impact level of the criteria is determined. The level of impact can be expressed as criteria priorities or criteria weights. In the proposed model, the criterion priorities were determined by the fuzzy AHP method. The third step is about identifying the distance of the alternatives to the target. For this purpose information content $\left(\mathrm{I}_{\mathrm{i}}\right)$ values for all alternatives are calculated via the AD method. Finally, the most appropriate alternative is selected according to weighted information content values.

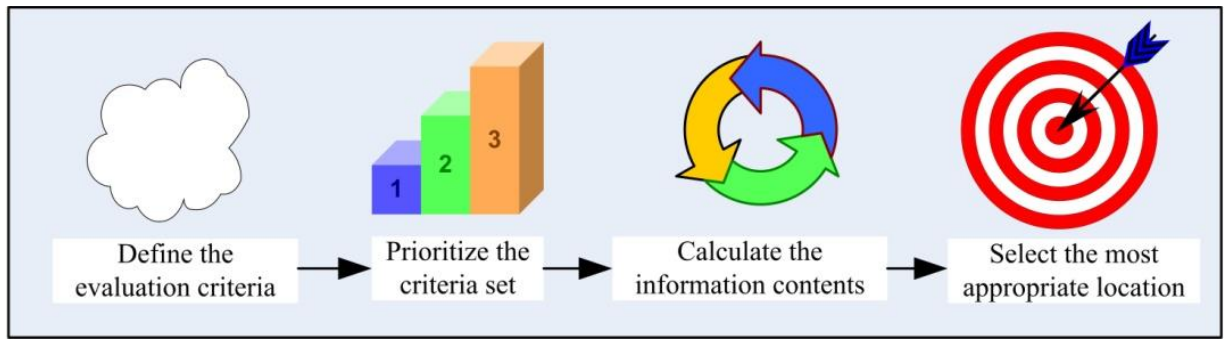

Figure 3. Main steps of the proposed model

\section{Application}

In this study, a model was proposed for selecting the location of the installation of the wind turbines by using fuzzy AHP and fuzzy AD methods. In the first stage, five evaluation criteria were selected for location selection. These criteria are explained in Table 2.

Table 2. Evaluation Critera

\begin{tabular}{|c|c|c|}
\hline No & Criteria & Description \\
\hline 1 & Wind speed $(\mathrm{m} / \mathrm{s})$ & $\begin{array}{l}\text { Represents annual average wind speed in the location. It has great } \\
\text { influence on the energy to be produced. }\end{array}$ \\
\hline 2 & Wind power density $\left(\mathrm{W} / \mathrm{m}^{2}\right)$ & Annual mean wind power density above the surface \\
\hline 3 & Capacity factor $(\%)$ & Average power generated, divided by the rated peak power \\
\hline 4 & Distance to power grid & It is a criterion that affects installation cost \\
\hline 5 & Land roughness value & $\begin{array}{l}\text { If the roughness (forest and shrub) in the land increases, the wind speed } \\
\text { decreases. }\end{array}$ \\
\hline
\end{tabular}

The effect of each criterion is different. For this reason, the effect of the criteria was determined with the fuzzy AHP method by using Equations (1-9) in the second stage. DMs evaluated all the criteria by making pairwise comparisons between the criteria. Linguistic expressions of DMs were translated into triangular fuzzy numbers with the help of Table 1. Fuzzy pairwise comparisons of the criteria are shown in Table 3.

Table 3. Fuzzy pair-wise comparison matrix of five selection criteria

\begin{tabular}{cccccc}
\hline & \multicolumn{5}{c}{ Triangular Fuzzy Numbers } \\
& $\mathrm{C} 1$ & $\mathrm{C} 2$ & $\mathrm{C} 3$ & $\mathrm{C} 4$ & $\mathrm{C} 5$ \\
\hline $\mathrm{C} 1$ & $(1 ; 1 ; 1)$ & $(1 ; 3 ; 5)$ & $(1 ; 3 ; 5)$ & $(5 ; 7 ; 9)$ & $(3 ; 5 ; 7)$ \\
$\mathrm{C} 2$ & $(1 / 5 ; 1 / 3 ; 1)$ & $(1 ; 1 ; 1)$ & $(1 ; 3 ; 5)$ & $(3 ; 5 ; 7)$ & $(1 ; 3 ; 5)$ \\
C3 & $(1 / 5 ; 1 / 3 ; 1)$ & $(1 / 5 ; 1 / 3 ; 1)$ & $(1 ; 1 ; 1)$ & $(3 ; 5 ; 7)$ & $(1 ; 3 ; 5)$ \\
C4 & $(1 / 9 ; 1 / 7 ; 1 / 5)$ & $(1 / 7 ; 1 / 5 ; 1 / 3)$ & $(1 / 7 ; 1 / 5 ; 1 / 3)$ & $(1 ; 1 ; 1)$ & $(1 ; 3 ; 5)$ \\
C5 & $(1 / 7 ; 1 / 5 ; 1 / 3)$ & $(1 / 5 ; 1 / 3 ; 1)$ & $(1 / 5 ; 1 / 3 ; 1)$ & $(1 / 5 ; 1 / 3 ; 1)$ & $(1 ; 1 ; 1)$ \\
\hline
\end{tabular}


Criteria weights are presented in Table 4. The most important three criteria are listed as criteria 1 (wind speed), criteria 2 (wind power density) and criteria 3 (capacity factor). The least important criterion is criteria 5 (land roughness value). All criteria with different weights were taken into consideration.

Table 4. The results of fuzzy AHP for evaluation criteria

\begin{tabular}{ll}
\hline Evaluation Criteria & Criteria Weights \\
\hline C1: Wind speed (WS) & 0.362 \\
C2: Wind power density (WPD) & 0.29 \\
C3: Capacity factor (CF) & 0.245 \\
C4: Distance to power grid (DPG) & 0.093 \\
C5: Land roughness value (LRV) & 0.01 \\
\hline
\end{tabular}

In the third stage, alternative locations have been evaluated with the fuzzy AD approach. The company's design ranges are as follows:

- $\mathrm{FR}_{\mathrm{WS}}=$ Wind speed must be over $5 \mathrm{~m} / \mathrm{s}$

- $\mathrm{FR}_{\mathrm{WPD}}=$ Wind power density must be over $400 \mathrm{~W} / \mathrm{m}^{2}$

- $\mathrm{FR}_{\mathrm{CF}}=$ Capacity factor must be over $\% 25$

- $\quad \mathrm{FR}_{\mathrm{DPG}}=$ Distance to power grid must not be over $5000 \mathrm{~m}(0 ; 0 ; 5000)$

- $\mathrm{FR}_{\mathrm{LRV}}=\mathrm{Land}$ roughness value (LRV) must not be over $6(0 ; 0 ; 6)$

Minimum and maximum performance values of the alternative locations are given Table 5.

Table 5. The system range data for evaluation criteria

\begin{tabular}{lccc}
\hline & \multicolumn{3}{c}{ Alternative Locations } \\
& Loc-A & Loc-B & Loc-C \\
\hline Wind speed (WS) & $4-6 \mathrm{~m} / \mathrm{s}$ & $5-7 \mathrm{~m} / \mathrm{s}$ & $3-6 \mathrm{~m} / \mathrm{s}$ \\
Wind power density (WPD) & $300-500 \mathrm{~W} / \mathrm{m} 2$ & $300-600 \mathrm{~W} / \mathrm{m} 2$ & $250-450 \mathrm{~W} / \mathrm{m} 2$ \\
Capacity factor (CF) & $\% 25-30$ & $\% 20-40$ & $\% 15-30$ \\
Distance to power grid (DPG) & Very Good & Very Good & Fair \\
Land roughness value (LRV) & Semi-Rough & Smooth & Semi-Rough \\
\hline
\end{tabular}

\section{Results}

DMs evaluated the three alternative locations (Loc-A, Loc-B, and Loc-C) with respect to evaluation criteria. The DMs used the linguistic expressions about the distance to power grid and land roughness value criteria. Figure 4 and Figure 5 shows the membership functions of the linguistic expressions about distance to power grid and land roughness value criteria respectively.

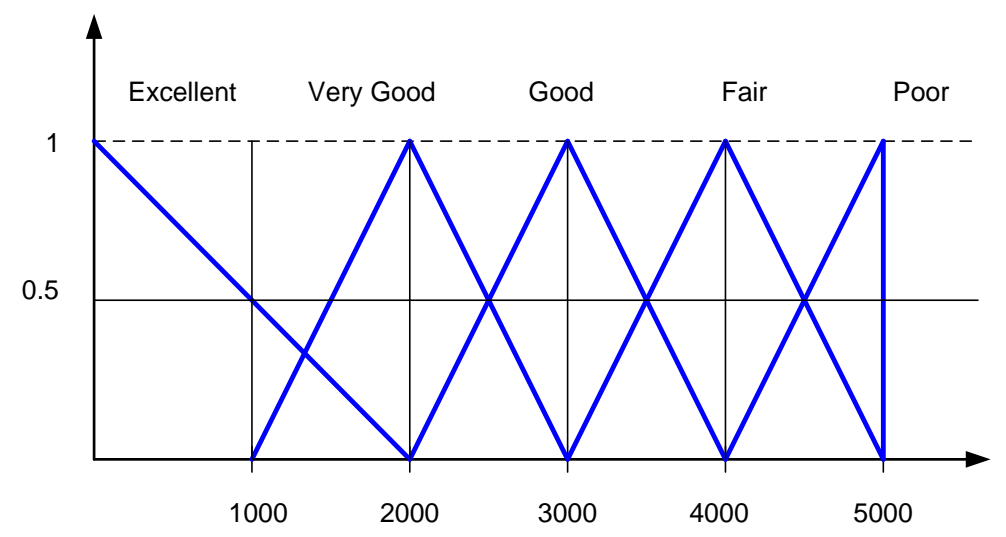

Figure 4. TFNs for intangible factors (distance to power grid) 


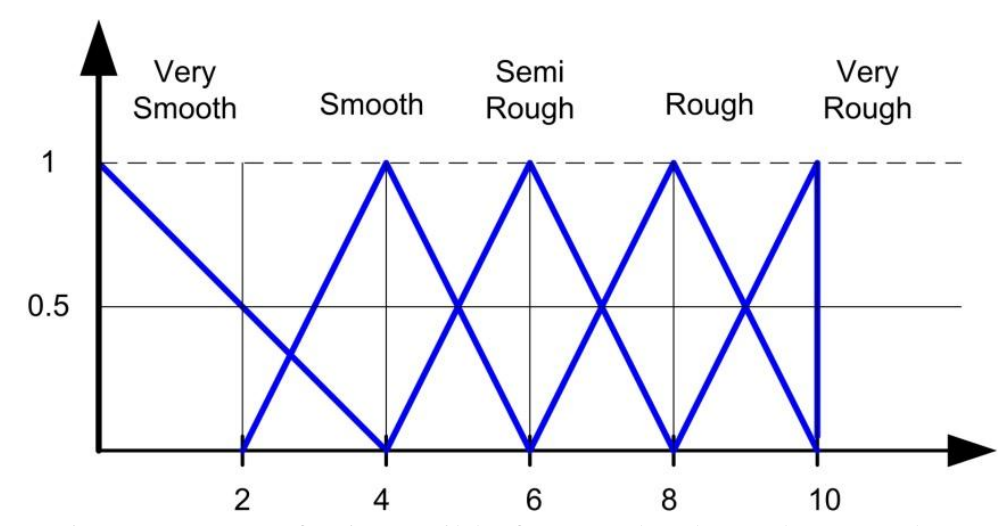

Figure 5. TFNs for intangible factors (land roughness value)

The information content for tangible factors can be computed using Eq. (12). For instance, the information contents of alternative locations according to the wind speed criterion $\left(\mathrm{I}_{\mathrm{WS}}\right)$ are calculated as follows;

for Loc-A: $I_{W S}=\log _{2}\left(\frac{\text { system range }}{\text { common range }}\right)=\log _{2}\left(\frac{6-4}{6-5}\right)=1$

for Loc-B: $I_{W S}=\log _{2}\left(\frac{\text { system range }}{\text { common range }}\right)=\log _{2}\left(\frac{7-5}{7-5}\right)=0$

for Loc-A: $I_{W S}=\log _{2}\left(\frac{\text { system range }}{\text { common range }}\right)=\log _{2}\left(\frac{6-3}{6-5}\right)=1.584$

All tangible factors are calculated according to Eq. (12) as shown in the above example. DPG and LRV criteria are linguistic variables. For this reason, it is necessary to calculate common triangular areas. The information content for DPG and LRV criteria can be computed using Eq. (13). For instance, design range, system range and common area for distance to power grid (DPG) criteria for location A are shown in Figure 6.

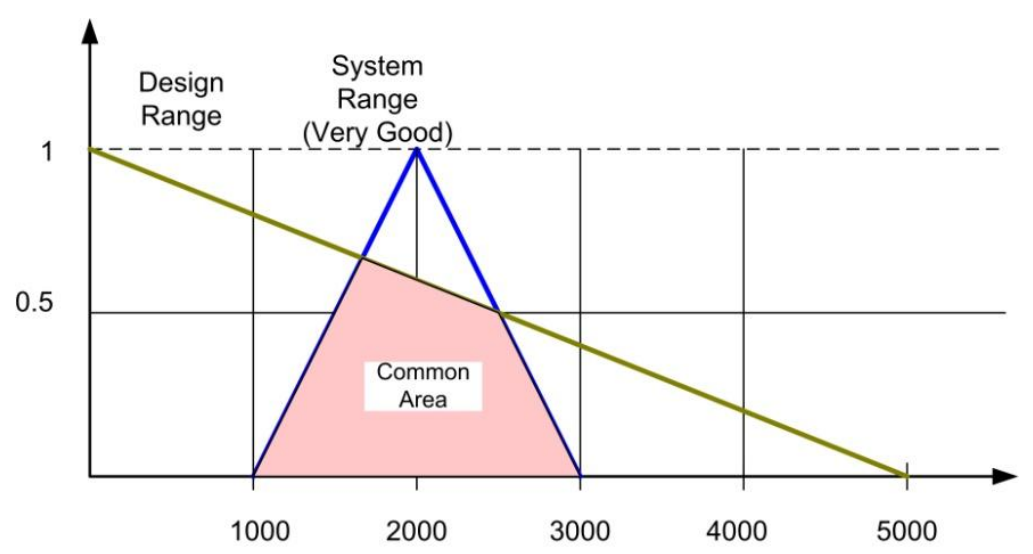

Figure 6. Design and system ranges of DPG for Loc-A

The information contents for the evaluation criteria with respect to the alternative locations are given in Table 6.

Table 6. The Results of Information Content for Locations

\begin{tabular}{ccccccc}
\hline Criteria Weights & 0.362 & 0.29 & 0.245 & 0.093 & 0.01 & \\
\hline Alternatives & $\mathrm{I}_{\mathrm{WS}}$ & $\mathrm{I}_{\mathrm{WPD}}$ & $\mathrm{I}_{\mathrm{CF}}$ & $\mathrm{I}_{\mathrm{DPG}}$ & $\mathrm{I}_{\mathrm{LRV}}$ & $\sum \mathrm{I}$ \\
\hline Loc-A & 1 & 1 & 0 & 0.263 & 3 & 5.263 \\
Loc-B & 0 & 0.585 & 0.415 & 0.263 & 1 & $2.263^{*}$ \\
Loc-C & 1.584 & 2 & 0 & 1.585 & 3 & 8.169 \\
\hline
\end{tabular}


The values in Table 6 are valid if all the criteria are equal. In this study, the weights of the criteria are different. For this reason, the fuzzy AD approach [32] was used. Table 7 is obtained by using fuzzy AD approach using Eq. (14). As the location with minimum information content is the best one, Loc-B is selected.

Table 7. The Results of Weighted Information Content for Alternative Locations

\begin{tabular}{ccccccl}
\hline Alternatives & IWS & IWPD & ICF & IDPG & ILRV & $\sum$ I \\
\hline Loc-A & 0.362374 & 0.289863 & 0 & 0.000001 & 1.010739 & 1.662977 \\
Loc-B & 0 & 0.157259 & 0.027660 & 0.000001 & 0.009723 & $0.194642^{*}$ \\
Loc-C & 1.181371 & 2.000000 & 0 & 1.043713 & 1.010739 & 5.235822 \\
\hline
\end{tabular}

\section{Conclusions}

The renewable energy sources provide long-term economic benefits. The one and only return expected from renewable energy sources is not the economic benefit. Renewable energy sources are in focus because they are more sensitive to the environment. Location selection of wind energy plants is very important. Because this decision significantly affects the efficiency of the generated energy. There are many criteria that can be evaluated during the location selection process. Wind speed, wind power density are related to climatic conditions, while the distance to power grids is related to the physical location. Many different factors must be considered together for location selection. These factors may also be linguistically expressed. In this study, a model is proposed for the selection of the appropriate location for the installation of wind power plants. In the proposed model, multiple criteria were evaluated together with fuzzy AHP method, and criteria weights were determined. In the next step, the appropriate location was selected with the fuzzy AD method. In the future research for this study, sensitivity analysis can be done by changing the criteria weights. In addition, the results can be compared by calculating the criteria priorities with different MCDM methods.

\section{References}

[1] "Republic of Turkey Ministry of Energy and Natural Resources." [Online]. Available: http://www.enerji.gov.tr/en-US/Pages/Wind. [Accessed: 23-Oct-2018].

[2] C. Kahraman, I. Kaya, and S. Cebi, "A comparative analysis for multiattribute selection among renewable energy alternatives using fuzzy axiomatic design and fuzzy analytic hierarchy process," Energy, vol. 34, no. 10, pp. 1603-1616, 2009.

[3] C. Kahraman and I. Kaya, "A fuzzy multicriteria methodology for selection among energy alternatives," Expert Syst. Appl., vol. 37, no. 9, pp. 6270-6281, 2010.

[4] B. Wang, D. F. Kocaoglu, T. U. Daim, and J. Yang, "A decision model for energy resource selection in China,” Energy Policy, vol. 38, no. 11, pp. 7130-7141, 2010.

[5] J. R. San Cristóbal, "Multi-criteria decision-making in the selection of a renewable energy project in spain: The Vikor method," Renew. Energy, vol. 36, no. 2, pp. 498-502, 2011.

[6] F. E. Boran, K. Boran, and T. Menlik, "The Evaluation of Renewable Energy Technologies for Electricity Generation in Turkey Using Intuitionistic Fuzzy TOPSIS," Energy Sources, Part B Econ. Planning, Policy, vol. 7, no. 1, pp. 81-90, 2012.

[7] O. Demirtas, "Evaluating the Best Renewable Energy Technology for Sustainable Energy Planning," Int. J. Energy Econ. Policy, vol. 3, pp. 23-33, 2013.

[8] S. Ahmad and R. M. Tahar, "Selection of renewable energy sources for sustainable development of electricity generation system using analytic hierarchy process: A case of Malaysia," Renew. Energy, vol. 63, pp. 458-466, 2014.

[9] Y. Çelikbilek and F. Tüysüz, "An integrated grey based multi-criteria decision making approach for the evaluation of renewable energy sources," Energy, vol. 115, pp. 1246-1258, 2016.

[10] H. Aras, Ş. Erdoğmuş, and E. Koç, "Multi-criteria selection for a wind observation station location using analytic hierarchy process," Renew. Energy, vol. 29, no. 8, pp. 1383-1392, 2004.

[11] J. Zhu and K. Cheung, "Selection of wind farm location based on fuzzy set theory," in IEEE PES General Meeting, 2010, pp. 1-6.

[12] A. Azadeh, S. F. Ghaderi, and M. R. Nasrollahi, "Location optimization of wind plants in Iran by an integrated hierarchical Data Envelopment Analysis," Renew. Energy, vol. 36, no. 5, pp. 1621-1631, 2011. 
[13] R. Van Haaren and V. Fthenakis, "GIS-based wind farm site selection using spatial multi-criteria analysis (SMCA): Evaluating the case for New York State," Renew. Sustain. Energy Rev., vol. 15, no. 7, pp. 3332-3340, 2011.

[14] D. Choudhary and R. Shankar, "An STEEP-fuzzy AHP-TOPSIS framework for evaluation and selection of thermal power plant location: A case study from India," Energy, vol. 42, no. 1, pp. 510$521,2012$.

[15] W. Yun-Na, Y. Yi-Sheng, F. Tian-Tian, K. Li-Na, L. Wei, and F. Luo-Jie, "Macro-site selection of wind/solar hybrid power station based on Ideal Matter-Element Model," Int. J. Electr. Power Energy Syst., vol. 50, pp. 76-84, 2013.

[16] N. C. Chatterjee and G. K. Bose, "A COPRAS-F base multi-criteria group decision making approach for site selection of wind farm," Decis. Sci. Lett., vol. 2, no. 1, pp. 1-10, 2013.

[17] K. B. Atici, A. B. Simsek, A. Ulucan, and M. U. Tosun, "A GIS-based Multiple Criteria Decision Analysis approach for wind power plant site selection," Util. Policy, vol. 37, pp. 86-96, 2015.

[18] D. Latinopoulos and K. Kechagia, "A GIS-based multi-criteria evaluation for wind farm site selection. A regional scale application in Greece," Renew. Energy, vol. 78, pp. 550-560, 2015.

[19] S. Ali, S.-M. Lee, and C.-M. Jang, "Determination of the most optimal on-shore wind farm site location using a GIS-MCDM methodology: Evaluating the case of South Korea," Energies, vol. 10, no. 12, pp. 1-22, 2017.

[20] C.-N. Wang, V. T. Nguyen, H. T. N. Thai, and D. H. Duong, "Multi-criteria decision making (MCDM) approaches for solar power plant location selection in Viet Nam," Energies, vol. 11, no. 6, pp. 1-27, 2018.

[21] B. Daneshvar Rouyendegh, A. Yildizbasi, and Ü. Z. B. Arikan, "Using intuitionistic fuzzy TOPSIS in site selection of wind power plants in Turkey," Adv. Fuzzy Syst., vol. 2018, pp. 1-14, 2018.

[22] F. E. Boran, T. Menlik, and K. Boran, "Multi-criteria Axiomatic Design Approach to Evaluate Sites for Grid-connected Photovoltaic Power Plants: A Case Study in Turkey," Energy Sources, Part B Econ. Planning, Policy, vol. 5, no. 3, pp. 290-300, 2010.

[23] A. V. Khandekar, J. Antuchevičienè, and S. Chakraborty, "Small hydro-power plant project selection using fuzzy axiomatic design principles," Technol. Econ. Dev. Econ., vol. 21, no. 5, pp. 756-772, 2015.

[24] M. F. Ariza Taba, M. Mwanza, N. S. Çetin, and K. Ülgen, "Assessment of the energy generation potential of photovoltaic systems in Caribbean region of Colombia," Period. Eng. Nat. Sci., vol. 5, no. 1, pp. 55-60, 2017.

[25] M. Mwanza, J. Chachak, N. S. Çetin, and K. Ülgen, "Assessment of Solar Energy Source Distribution and Potential in Zambia," Period. Eng. Nat. Sci., vol. 5, no. 2, pp. 103-116, 2017.

[26] M. K. Yeşilyurt, İ. V. Öner, G. Ömeroğlu, and E. Ç. Yılmaz, "A scrutiny study on wave energy potential and policy in TURKEY,” Period. Eng. Nat. Sci., vol. 5, no. 3, pp. 286-297, 2017.

[27] T. L. Saaty, The analytic hierarchy process. New York, USA: McGraw-Hill, 1980.

[28] D.-Y. Chang, "Applications of the extent analysis method on fuzzy AHP," Eur. J. Oper. Res., vol. 95, no. 3, pp. 649-655, 1996.

[29] N. P. Suh, The Principles of Design. New York: Oxford University Press, 1990.

[30] N. P. Suh, Axiomatic Design Advances and Applications. New York: Oxford University Press, 2001.

[31] C. Kahraman, S. Cebi, and İ. Kaya, "Selection among Renewable Energy Alternatives Using Fuzzy Axiomatic Design: The Case of Turkey," J. Univers. Comput. Sci., vol. 16, no. 1, pp. 82-102, 2010.

[32] O. Kulak and C. Kahraman, "Fuzzy multi-attribute selection among transportation companies using axiomatic design and analytic hierarchy process," Inf. Sci. (Ny)., vol. 170, no. 2-4, pp. 191-210, 2005.

[33] O. Kulak and C. Kahraman, "Multi-attribute comparison of advanced manufacturing systems using fuzzy vs. crisp axiomatic design approach," Int. J. Prod. Econ., vol. 95, no. 3, pp. 415-424, 2005.

[34] O. Kulak, M. B. Durmuşoğlu, and C. Kahraman, "Fuzzy multi-attribute equipment selection based on information axiom," J. Mater. Process. Technol., vol. 169, no. 3, pp. 337-345, 2005. 